\title{
Conditional QTL mapping for waterlogging tolerance in two RILs populations of wheat
}

\author{
Ma Yu and Guo-Yue Chen ${ }^{*}$
}

\begin{abstract}
Waterlogging is a widespread limiting factor for wheat production throughout the world, specially irrigated and high rainfall environments. Only few studies reported QTLs for waterlogging tolerance. To identify quantitative trait loci (QTLS) for waterlogging tolerance, root dry weight index (RDWI), shoot dry weight index (SDWI), total dry weight index (TDWI) were measured at seedling stage in two unrelated recombinant inbred lines (RILs) populations. These populations were International Triticeae Mapping Initiative (ITMI) population 'W7984 / Opata85', and 'SHWL1 $\times$ Chuanmai 32' (SC) population. Conditional QTL mapping and unconditional QTL mapping were studied to dissect the genetic relationship between TDWI and its components of SDWI and TDWI. Total of 36 QTLs for waterlogging tolerance in ITMI population and 10 QTLs in SC population were identified in present study. Of them, 17 alleles from synthetic hexaploid wheat 'W7984' and 3 alleles from synthetic hexaploid wheat 'SHW-L1' contribute positively to waterlogging tolerance. Combinations of conditional and unconditional mapping methods indicate that SDWI showed tighter genetic correlation with TDWI than RDWI. This QTL identification study and dissection provide theoretical basis and application foundation to Marker-assisted selection (MAS) of waterlogging tolerance improvement in wheat.
\end{abstract}

Keywords: QTL, Waterlogging tolerance, Conditional and unconditional mapping

\section{Background}

Waterlogging is a widespread limiting factor for wheat production throughout the world specially irrigated and high rainfall environments. About 10-15 million ha of the world's wheat growing areas are affected by waterlogging each year (Sayre et al. 1994), representing $15-20 \%$ of the 70 million ha annually cultivated for wheat production, especially in south and south-east Asia including Bangladesh, Pakistan, India, Nepal and China (Samad et al. 2001; Settler and Waters 2003). The breeding and cultivation of resistant wheat cultivars is the most promising strategy to reduce the risk of waterlogging. MAS could be a promising tool to facilitate the selection of resistant cultivars and to enhance breeding efficiency.

Waterlogging tolerance is defined as the survival or the maintenance of growth rates under waterlogging to nonwaterlogged conditions (Settler and Waters 2003). In previous studies, traits have been measured include

\footnotetext{
* Correspondence: yuwen.0073@hotmail.com

Triticeae Research Institute, Sichuan Agricultural University, 211 Huimin Road, Wenjiang, Chengdu, Sichuan 611130, China
}

plant height, growth increment, and shoot or root dry weight (Burgos et al. 2001; Boru et al. 2001; Qiu et al. 2007; Li et al. 2008; Parelle et al. 2010). In early stage of wheat, the maintenance of biomass in waterlogging is of major importance from agronomic view (Parelle et al. 2010). It also associated biomass distribution between overground and subterraneous organs. Therefore, maintenance of shoot dry weight, root dry weight, and total dry weight can be used as indicators for waterlogging tolerance in wheat.

Genetic diversity for waterlogging tolerance existed in wheat (Huang et al. 1994; Setter et al. 1999). However, QTLs for waterlogging tolerance have been reported in few studies (Poysa 1984; Taeb et al. 1993; Burgos et al. 2001; Boru et al. 2001). In addition, one dominant gene controlling tolerance of waterlogging was detected in both wheat and barley (Cao et al. 1995; Zhou et al. 2007). These studies indicate that waterlogging tolerance is a complex trait, and classical genetic studies are limited. More recently, a method for multivariable conditional analysis was proposed for analyzing the contributions of component traits to a complex trait and

\section{实}


for investigating the genetic relationship between two traits at the QTL level (Wen and Zhu 2005). This method may dissect genetic relationships between maintenance ability of shoot dry weight (or root dry weight) and total dry weight under waterlogging condition.

In present study, we performed QTL detection for TDWI, RDWI, and SDWI at seedling stage in two unrelated recombinant inbred lines (RILs) populations, both of which were developed by hybrid with synthetic hexaploid wheat. Conditional study based on Wen and Zhu was also analyzed (Wen and Zhu 2005). The objectives of this study were to: (1) understand the genetic control of waterlogging tolerance. (2) specify the genetic relationships between maintenance ability of shoot dry weight (or root dry weight) and total dry weight under waterlogging at QTL level.

\section{Results}

\section{Phenotypic summary}

Significant dry weight loss in mean value was observed in ITMI and SC populations during waterlogging treatment. Commercial cultivar 'opata85' showed higher waterlogging tolerance index for SDW, RDW, and TDW than synthetic wheat 'W7984' in ITMI population (Table 1). However, synthetic wheat 'SHW-L1' showed higher SDWI and TDWI than Commercial cultivar 'Chuanmai 32' in SC population (Table 2). All investigated traits following waterlogging stress showed transgressive segregation in both RILs populations. All traits segregated continuously and followed a normal distribution in both populations. In correlation analysis, SDWI, RDWI, and TDWI showed significant positive correlation (Table 3).

\section{QTL mapping in ITMI population}

Total of 36 QTLs were identified on 18 chromosomes in ITMI population, and they explained $0.8-28.2 \%$ of the phenotypic variation (Table 4). Of these QTLs, 17 alleles from synthetic hexaploid wheat 'W7984' contributed positively to waterlogging tolerance, and the other 19 alleles from 'Opata85' contributed positively. Total of 10 common QTL regions were identified in present study, which carried 2 to 4 QTLs, especially the region of XksuH14-Xfbb364 on 6B which carried QTLs for RDWI, SDWI, TDWI, and $y_{\text {(TDWI|SDWI) }}$ (Figure 1).
Total of 18 QTLs were detected on 12 chromosomes in unconditional analysis, 8 of which were identified for RDWI, 7 QTLs were found for SDWI, and the rest 3 QTLs were detected for TDWI (Table 4). For these three investigated traits, 4 alleles from 'Opata85' contributed positively to RDWI, 3 alleles from 'W7984' contributed positively to SDWI, and 2 alleles from 'W7984' contributed positively to TDWI. Phenotypic variances explained by these QTLs varied from 4.2- 18.0\%.

For conditional analysis, 18 QTLs were identified on 13 chromosomes (Table 4). Of these QTLs, 3 QTLs were identified for $y_{\text {(TDWI|RDWI) }}$, and the rest 15 QTLs were identified for $y_{\text {(TDWI SDWI). For these two conditional }}$ traits, 2 alleles from 'W7984' contributed positively to $y_{\text {(TDWI|RDWI) }}$, and 10 alleles from 'Opata85' contributed

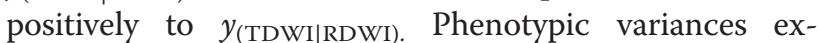
plained by these QTLs varied from $0.8-28.2 \%$.

\section{QTL mapping in SC population}

Total of 10 QTLs were identified on 6 chromosomes in SC population, and they explained 5.3- 29.3\% (Table 5). Of these QTLs, 3 alleles from synthetic hexaploid wheat 'SHW-L1' contributed positively to waterlogging tolerance, and the other 7 alleles from 'Chuanmai 32' contributed positively. Total of 3 common QTL regions were identified in present study (Figure 2). These regions were located on $4 \mathrm{~B}$ and $7 \mathrm{~B}$, and every region carried two QTLs.

For unconditional analysis, 7 QTLs were identified 5 chromosomes (Table 5). Of these QTLs, 3 of which were identified for RDWI, only one QTL was detected for SDWI, and the rest 3 QTLs were found for TDWI. For these three investigated traits, all alleles from 'Chuanmai 32 ' contributed positively to phenotypic variation, except QTLs for TDWI on 6B and 6D. Phenotypic variances explained by these QTLs varied from 5.9- 13.2\%.

For conditional analysis, none QTLs were detected for $y_{\text {(TDWI|RDWI) }}$, and 3 QTLs were identified for $y_{\text {(TDWI|SDWI) }}$ (Table 5). These QTLs were located on 3D, 4B, and 7B, with phenotypic explanation of $29.3 \%, 5.3 \%$ and $6.4 \%$. For QTLs on 3D, alleles from 'SHW-L1' contributed positively to phenotypic variation. Whereas the rest alleles from 'Chuanmai 32' contributed positively to $y_{\text {(TDWI. }}$

Table 1 Phenotypic variations of waterlogging tolerance index in ITMI population

\begin{tabular}{|c|c|c|c|c|c|c|c|c|c|}
\hline \multirow[t]{2}{*}{ Trait $^{a}$} & \multicolumn{2}{|c|}{ Parents } & \multicolumn{7}{|c|}{ RILs population } \\
\hline & Opata85 & W7984 & Min. & Max. & Mean & SD & $C V^{b}$ & Skewness & Kurtosis \\
\hline RDWI & 0.18 & 0.07 & 0.07 & 0.30 & 0.18 & 0.21 & 0.30 & 0.44 & 1.20 \\
\hline SDWI & 0.29 & 0.16 & 0.18 & 0.71 & 0.46 & 1.68 & 0.17 & -0.25 & -0.30 \\
\hline TDWI & 0.47 & 0.23 & 0.25 & 0.97 & 0.64 & 0.95 & 0.25 & -0.20 & 0.42 \\
\hline
\end{tabular}

${ }^{a}$ Traits were root dry weight index (RDWI), shoot dry weight index (SDWI), total dry weight index (TDWI).

${ }^{\mathrm{b}}$ Coefficient of variability. 
Table 2 Phenotypic variations of waterlogging tolerance index in SC population

\begin{tabular}{|c|c|c|c|c|c|c|c|c|c|}
\hline \multirow[t]{2}{*}{ Trait $^{a}$} & \multicolumn{2}{|c|}{ Parents } & \multicolumn{7}{|c|}{ RILs population } \\
\hline & Chuanmai 32 & SHW-L1 & Min. & Max. & Mean & SD & $\mathrm{CV}^{\mathbf{b}}$ & Skewness & Kurtosis \\
\hline RDWI & 0.19 & 0.09 & 0.02 & 0.36 & 0.23 & 0.19 & 0.29 & -0.35 & -0.09 \\
\hline SDWI & 0.32 & 0.49 & 0.19 & 0.81 & 0.45 & 0.17 & 0.25 & -0.19 & -0.42 \\
\hline TDWI & 0.51 & 0.58 & 0.28 & 1.00 & 0.68 & 0.16 & 0.23 & -0.16 & -0.31 \\
\hline
\end{tabular}

${ }^{\mathrm{a}}$ and ${ }^{\mathrm{b}}$ can referred to Table 1 .

\section{Genetic relation between RDWI (or SDWI) and TDWI}

Biologically, the value of TDWI equals RDWI plus TDWI. There were 5 results when performing conditional QTL mapping analysis, such as the conditional QTL analysis of TDWI conditioned on RDWI: 1) a QTL detected for TDWI can be also identified for RDWI with a similar or equal effect, but can't identified effect for $y_{\text {(TDWI|RDWI) }}$, this indicate that this QTL for TDWI is entirely contributed by RDWI. 2) a QTL for TDWI was identified for RDWI and $y_{(\mathrm{TDWI} / \mathrm{RDWI})}$, this suggest that this QTL for TDWI is partly contributed by RDWI. 3) a QTL for TDWI only identified for $y_{\text {(TDWI|RDWI) }}$, this indicate that this QTL for TDWI is independent of RDWI. 4) an additional QTL only identified for $y_{(\mathrm{TDWI} \mid \mathrm{RDWI})}$, which means that the expression of the QTL for TDWI is contributed by SDWI or suppressed by RDWI. 5) a QTL only identified for RDWI, this means that this QTL for RDWI have no effect on TDWI.

Of the 3 QTLs for TDWI in ITMI population, 2 of which were entirely contributed by SDWI and the rest QTL was partly contributed by SDWI and RDWI. In SC population, 2 QTLs for TDWI were independent to SDWI and RDWI, and 1 QTL was entirely contributed by SDWI.

Total of 8 QTLs for RDWI in ITMI population were identified, only 1 of which entirely contributed to expression of the QTL for TDWI, 3 QTLs showed genetic

Table 3 Correlation coefficient among waterlogging tolerance index and conditional traits in ITMI and SC populations

\begin{tabular}{llllll}
\hline & RDWI $^{\mathbf{a}, \mathbf{b}}$ & $\mathbf{S D W I}$ & TDWI & $\mathbf{y}_{\text {(TDWI|RDWI) }}^{\mathbf{c}}$ & $\mathbf{y}_{\text {(TDWI|SDWI) }}$ \\
\hline $\mathrm{RDWI}$ & 1.00 & $0.43^{* *}$ & $0.73^{* *}$ & 0.00 & $0.83^{* *}$ \\
$\mathrm{SDWl}$ & $0.57^{* *}$ & 1.00 & $0.91^{* *}$ & $0.88^{* *}$ & 0.00 \\
$\mathrm{TDW} \mid$ & $0.79^{* *}$ & $0.96^{* *}$ & 1.00 & $0.68^{* *}$ & $0.41^{* *}$ \\
$\mathrm{y}_{\text {(TDW|RDWI) }}$ & 0.00 & $0.82^{* *}$ & $0.61^{* *}$ & 1.00 & $-0.28^{* *}$ \\
$\mathrm{y}_{\text {(TDW|SDWI) }}$ & $0.83^{* *}$ & 0.02 & $0.31^{* *}$ & $-0.56^{* *}$ & 1.00 \\
\hline
\end{tabular}

${ }^{a}$ Data in lower left quarter of the matrix was the correlation coefficient in ITMI population whereas data in top right corner was the correlation coefficient in SC population.

$\mathrm{b} * *$ significant $r$-values $\mathrm{p}<0.01$

c Conditional phenotypic values $y_{(\text {TDWI|RDWI) }}$ or $y_{\text {(TDW||SDWI) }}$ indicate the value of TDWI without the influences of RDWI or SDWI, Other abbreviations for traits and environments can refer to Table 1. coordination with SDWI to suppressed the expression of QTL for TDWI, and the rest 4 QTLs were independent to TDWI. In SC population, 3 QTLs for RDWI were identified, 2 of which coordinated with SDWI to suppressed the expression of QTL for TDWI.

For SDWI, 7 QTLs were identified in ITMI population, 3 of which showed contribution to TDW, 2 QTLs were suppressed the expression of QTL for TDWI, and the rest 2 QTLs have no effect on TDWI. Only one QTL was detected for SDWI in SC population, and this QTL affected TDWI independently.

\section{Discussion}

\section{QTL mapping}

Although no significant difference for RDWI existed among two commercial parents and two synthetic parents between two RILs populations, QTLs number for RDWI in ITMI population was more than that in SC population. QTLs number variation also existed for SDWI, $y_{\text {(TDWI SDWI) }}$, and $y_{\text {(TDWI SDWI) }}$ in ITMI population and SC population. For identified QTLs, chromosome locations were also different in two populations, except QTLs for $y_{\text {(TDWI|SDWI) }}$ on 3D and 4B, and QTL for total dry weight index on $6 \mathrm{~B}$ (Table 4 , Table 5). These identification variations might due to the different genetic background among two populations.

To our knowledge, there were only few studies reported QTLs for waterlogging tolerance (Taeb et al. Taeb et al. 1993; Poysa 1984; Burgos et al. 2001). Boru et al. found that up to 4 genes controlled waterlogging tolerance (Boru et al. 2001). However, this study lacks genetic map as framework to identify chromosome location. In previous studies, QTLs for waterlogging were reported on homologous group 3, 4 and 5 (Taeb et al. 1993; Poysa 1984; Burgos et al. 2001). Ma et al. identified a QTL associated with salt tolerance through measurement of shoot weight index (Ma et al. 2007). We also identified same chromosome locations in ITMI population and SC population, except 4A (Table 4, Table 5).

Genetic relation analysis between RDWI, SDWI and TDWI indicated that SDWI showed tighter genetic correlation with TDWI than RDWI in both ITMI population and SC population. Several QTLs for RDWI were coordinated with SDWI to affect the expression of QTL for TDWI, and 
Table 4 Unconditional and conditional QTL mapping with significant LOD values in the ITMI population

\begin{tabular}{|c|c|c|c|c|c|c|}
\hline \multirow[t]{2}{*}{ Chrom } & \multirow[t]{2}{*}{ Interval marker } & \multicolumn{5}{|c|}{$\mathrm{R}^{2} / \mathrm{LOD}^{\mathrm{a}}$} \\
\hline & & RDWI & $\mathbf{y}_{(\mathrm{TDW} \mid \mathrm{RDWI})}$ & SDWI & $\mathbf{y}_{(\mathrm{TDWI} \mid \mathrm{SDWI})}$ & TDWI \\
\hline $1 \mathrm{~A}$ & Xgwm357-Xbcd1407 & & & $-12.3 / 7.3$ & & \\
\hline 1B & Xgwm550-Xgwm33 & $-12.8 / 7.9$ & & & & \\
\hline \multirow[t]{2}{*}{ 1D } & Xpsr11-XksuD14 & & & & $-1.6 / 6.0$ & \\
\hline & Xgwm337-Xbarc229 & $-6.6 / 4.6$ & & & & \\
\hline $2 \mathrm{~A}$ & Xgwm47-Xgwm312 & & & & $-1.8 / 6.2$ & \\
\hline \multirow[t]{2}{*}{$2 B$} & Xgwm129-Xwg996 & & & & $4.9 / 15.4$ & \\
\hline & Xfba385-Xfba310 & & $28.2 / 10.2$ & & $-7.1 / 20.0$ & \\
\hline $2 \mathrm{D}$ & Xcmwg682-Xbcd718 & & & $5.4 / 2.5$ & & $6.9 / 2.6$ \\
\hline \multirow[t]{2}{*}{$3 \mathrm{~A}$} & Xtam33-Xgwm480 & & & $12.9 / 5.4$ & 7.9/19.8 & \\
\hline & Xfbb322-XgbxG242 & 18.0/10.3 & & & & \\
\hline 3B & Xfba310-Xfbb293 & $4.2 / 3.1$ & & & & \\
\hline $3 \mathrm{D}$ & Xfbb316-XksuE14 & & & & $1.2 / 4.6$ & \\
\hline $4 \mathrm{~B}$ & Xgwm538-Xfbb67 & & & & $-3.3 / 11.2$ & \\
\hline $4 \mathrm{D}$ & Xfba177-Xgwm609 & & & & $-10.8 / 26.1$ & \\
\hline $5 \mathrm{~A}$ & Xbarc117-Xgwm129 & & & & $-7.1 / 19.7$ & \\
\hline $5 B$ & Xfba166-Xfba348 & & & $9.8 / 4.4$ & & $9.2 / 3.4$ \\
\hline $5 \mathrm{D}$ & Xfbb100-Xbcd1670 & 13.7/8.6 & & & $19.2 / 28.2$ & \\
\hline \multirow[t]{2}{*}{$6 \mathrm{~A}$} & Xpsr10-Xfba85 & $11.1 / 7.2$ & & $5.8 / 2.7$ & $-3.5 / 11.1$ & \\
\hline & Xcdo772-Xfbb170 & & $8.4 / 3.8$ & & $-16.9 / 33.9$ & \\
\hline $6 B$ & XksuH14-Xfbb364 & $-9.2 / 7.0$ & & $-6.5 / 3.2$ & $-7.3 / 19.1$ & $-11.2 / 4.0$ \\
\hline $6 \mathrm{D}$ & Xbcd1319-XksuD1 & & & & $-2.2 / 8.1$ & \\
\hline $7 \mathrm{~B}$ & Xbarc50-Xgwm 146 & & $-17.0 / 7.5$ & $-10.8 / 4.8$ & & \\
\hline $7 D$ & Xbarc105-Xwg420 & $-6.7 / 4.4$ & & & $0.8 / 3.1$ & \\
\hline
\end{tabular}

${ }^{a} R^{2}$ is the percentage of phenotypic variance. LOD is the LOD peak of the QTL. Negative signs indicate that 'W7984' alleles reduce phenotypic value whereas positive indicate that 'W7984' alleles increase the phenotypic value. Abbreviations for traits can refer to Tables 1 and 3 .

most of them showed suppression. Breakthrough these suppressed relationship will be notable improvement for waterlogging breeding in wheat.

\section{Utilization of synthetic wheat in wheat improvement for waterlogging tolerance}

Common wheat is considered as one of the most intolerant crop for waterlogging (Thomson et al. 1992). Utilization of wide hybridization with wild relatives in Triticeae to improve waterlogging tolerance should be a feasible way (King et al. 1997; Colmer et al. 2006; Munns et al. 2011). Although synthetic wheat 'W7984' showed poor phenotype in waterlogging treatment, we still identified 17 alleles from synthetic hexaploid wheat 'W7984' contributed positively to waterlogging tolerance. In addition, 3 alleles from synthetic hexaploid wheat 'SHW-L1' also were found contributed positively to waterlogging tolerance. These QTLs might be novel resources which can improve waterlogging tolerance for common wheat.

\section{Conclusions}

This study identified 36 QTLs for waterlogging tolerance in ITMI population, and 10 QTLs in SC population. Combinations of conditional and unconditional mapping methods dissect the genetic relationship between QTL for TDWI and its components. This QTL identification study and dissection provide theoretical basis and application foundation to MAS of waterlogging tolerance improvement in wheat.

\section{Methods}

Populations used for QTL analysis

The first population is the International Triticea Mapping Initiative (ITMI) population 'W7984 / Opata', which consists of 112 recombinant inbred lines (RILs) (Van Deynze et al. 1995). The female parent 'W7984' is synthetic hexaploid wheat and the male parent 'Opata85' is a commercial cultivar. The second population (SC) of 171 recombinant inbred lines derived from 


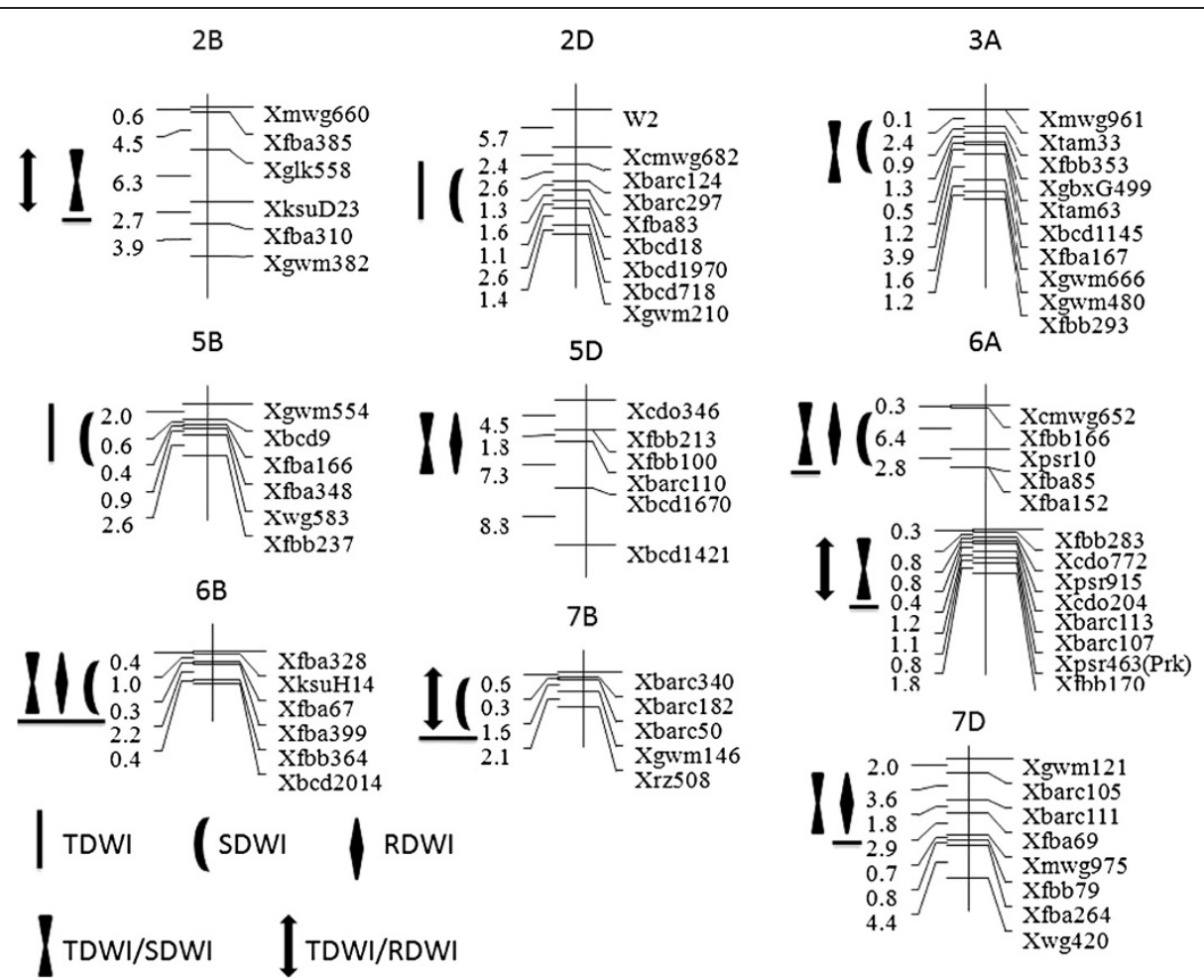

Figure 1 Unconditional and conditional QTL mapping with significant LOD values in the ITMI population. Only QTL clusters are shown in the figure. QTL with underline indicate that 'W7984' alleles reduce phenotypic value, whereas with no underline indicate 'W7984' alleles contributed positively. Abbreviations for traits and environments can refer to Tables 1 and 3.

the cross between 'SHW-L1' and 'Chuanmai 32'. The parents, Synthetic hexaploid wheat 'SHW-L1', was obtained through distant hybridization between accession AS2255 (AABB, T. turgidum ssp. turgidum) and AS60 (DD, Ae. tauschii ssp. tauschii) (Zhang et al. 2004), and 'Chuanmai 32' was a commercial wheat cultivar at southwest of China. Both parents of the synthetic wheat are sensitive to waterlogging, whereas both parents of the common wheat are tolerant to waterlogging in those two populations. All the materials were provided by Triticeae Institution, Sichuan Agricultural University, China.

\section{Evaluation of waterlogging tolerance}

Two replicates each with 20 disinfectant seeds which had been pre-selected for uniform mass. Seeds were germinated in water into plastic pots $(78.5 \mathrm{~cm}$ square by $15.8 \mathrm{~cm}$ in height) containing quartz gravel. After germination, 10 plants were kept in each pot and grown in a glasshouse under 16 hour's illumination a day. All pots

Table 5 Unconditional and conditional QTL mapping with significant LOD values in the SC population

\begin{tabular}{|c|c|c|c|c|c|c|}
\hline \multirow[t]{2}{*}{ Chrom } & \multirow[t]{2}{*}{ Interval marker } & \multicolumn{5}{|c|}{$\mathrm{R}^{2} / \mathrm{LOD}^{\mathrm{a}}$} \\
\hline & & RDWI & $\mathbf{y}_{\text {(TDWI|RDWI) }}$ & SDWI & $y_{(T D W I \mid S D W I)}$ & TDWI \\
\hline $3 \mathrm{D}$ & wPt-671868-wPt-741417 & & & & 29.3/23.0 & \\
\hline $4 \mathrm{~B}$ & wPt-730435-wPt-9625 & $-7.8 / 3$ & & & $-5.3 / 3.0$ & \\
\hline $5 B$ & wPt-6014-wPt-2607 & $-11.7 / 2.6$ & & & & \\
\hline $6 \mathrm{~B}$ & wPt-5037-wPt-9231 & & & & & $6.0 / 2.7$ \\
\hline $6 \mathrm{D}$ & wPt-730822-wPt-733873 & & & & & $11.2 / 3.0$ \\
\hline 7B & wPt-6156-wPt-5462 & & & $-5.7 / 2.5$ & & $-5.9 / 2.7$ \\
\hline 7B & wPt-3533-wPt-7653 & $-13.2 / 4.7$ & & & $-6.4 / 3.3$ & \\
\hline
\end{tabular}

${ }^{a}$ Negative signs indicate that 'SHW-L1' alleles reduce phenotypic value whereas positive indicate that 'SHW-L1' alleles increase the phenotypic value. Abbreviations for traits and environments can refer to Tables 1 and 3. Title description can refer to Table 4. 


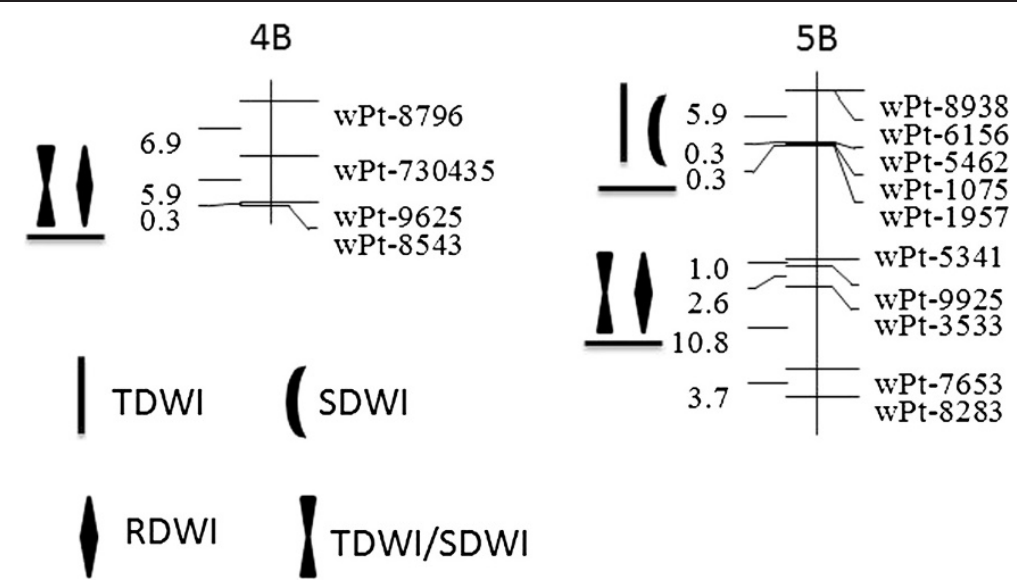

Figure 2 Unconditional and conditional QTL mapping with significant LOD values in the SC population. Only QTL clusters are shown in the figure. QTL with underline indicate that 'SHW-L1' alleles reduce phenotypic value. Abbreviations for traits and environments can refer to Tables 1 and 3.

for each replicate were placed in a single large plastic pool. Temperature was controlled at $18^{\circ} \mathrm{C}$ to $20^{\circ} \mathrm{C}$. Waterlogging was achieved by filling the pool with water to make sure that the tallest leaf tip was at least $10 \mathrm{~cm}$ below the water surface. Watelogging treatment was conducted after 7 days of germination, and continued for 7 days. After that, water level was treated the same as control in the experiments. Following the treatment, all plants in both control and treatment were cultured with modified Hoagland's nutrient solution in one week. Root dry weight, shoot dry weight, and total dry weight were measured. Waterlogging index calculated as values in waterlogging treatment divided by total dry weight in control.

\section{Statistical analysis}

Variance and covariance components were first analysised based on MINQUE method proposed by Zhu (1992). To estimate genotypic effect of the three traits via QGAStation 1.0 (http://ibi.zju.edu.cn/ software/qga/), data were assembled according to format of QTLData. QTLData menus of QGAStation 1.0 were selected followed Cui et al. (2013). Conditional phenotypic values $y_{(\mathrm{TDW} \mid \mathrm{SDW})}$ or $y_{(\mathrm{TDW} \mid \mathrm{RDW})}$ indicate the value of TDWI without the influences of SDWI or RDWI.

\section{Genetic map and QTL analysis}

Map date was downloaded from http://wheat.pw.usda. gov for ITMI population (Song et al. 2005). This map contained 1,410 loci (SSR and AFLP), covered 2, $541 \mathrm{cM}$ of genetic distance, with marker density of $1.72 \mathrm{cM} /$ marker in total.
For 'SHW-L1 $\times$ Chuanmai 32' (SC) population, two marker systems, DArT and SSR, were used for linkage map construction. A wheat DArT array consisting of 7,000 random markers were used for genotyping of the parents. DArT array was carried out by the Triticarte Pty. Ltd. (http://www.triticarte.com.au/). Procedures of hybridization of genomic DNA to the DArT array, image analysis and polymorphism scoring were as described by Akbari et al. (2006). Sixty-eight SSR markers polymorphic between two parents of the mapping population were also used for the linkage map construction. The genetic linkage map was constructed with JoinMap (version 4.0) (Van Ooijen, 2006), thresholds of recombination frequency from 0.05 to 0.20 were tested, and until a threshold with the optimum number of markers in linkage groups maintaining linkage order and distance was obtained. Known chromosomal locations of the SSR and DArT markers were used to assign linkage groups to specific chromosomes. ML (Maximum Likelihood) mapping function was used to order the loci belong one chromosome.

Inclusive composite interval mapping by IciMapping 2.0 was used based on stepwise regression of simultaneous consideration of all marker information ( $\mathrm{Li}$ et al. 2007). The walking speed for all QTLs was $1.0 \mathrm{cM}$, and LOD threshold set as 2.5. Both the observed phenotypic valuesand the conditional phenotypic values were used in QTL mapping analyses.

\section{Abbreviations}

QTLs: Quatitative trait loci; RDWI: Root dry weight index; SDWI: Shoot dry weight index; TDWI: Total dry weight index; RILs: Recombinant inbred line; ITMI: International triticeae mapping initiative population 'W7984 / Opata85'; SC: 'SHW-L1 × Chuanmai 32' population; MAS: Marker-assisted selection. 


\section{Competing interests}

Both authors report no competing interests.

\section{Authors' contributions}

MY designed the project, carried out research and drafted the manuscript. GYC contributed to project design, and revised the drafted manuscript. Both authors read and approved the final manuscript.

\section{Acknowledgements}

This work was supported by the National Natural Science Foundation of China (31171556, 31171555, 31230053)

\section{Received: 17 April 2013 Accepted: 23 May 2013}

Published: 27 May 2013

\section{References}

Akbari M, Wenzl P, Caig V, Carling J, Xia L, Yang S, Uszynski G, Mohler V, Lehmensiek A, Kuchel H, Hayden MJ, Howes N, Sharp P, Vaughan P, Rathnell B, Huttner E, Kilian A (2006) Diversity arrays technology (DArT) for highthroughput profiling of the hexaploid wheat genome. Theor Appl Genet 113:1409-1420

Boru G, Van GM, Kronstad WE, Boersma L (2001) Expression and inheritance of waterlogging tolerance stress in wheat. Euphytica 117:91-98

Burgos MS, Messmer MM, Stamp P, Chmid JE (2001) Flooding tolerance of spelt (Triticum spelta L.) compared to wheat (Triticum aestivum L.) - A physiological and genetic approach. Euphytica 122:287-295

Cao Y, Cai SB, Wu ZS, Zhu W, Fang XW, Xiong EH (1995) Studies on genetic features of waterlogging tolerance in wheat. Jiangsu Agricultural Sciences $11: 11-15$

Colmer TD, Flowers TJ, Munns R (2006) Use of wild relatives to improve salt tolerance in wheat. J Exp Bot 57:1059-1078

Cui F, Zhao CH, Li J, Ding AM, Li XF, Bao YG, Li JM, Ji J, Wang HG (2013) Kernel weight per spike: what contributes to it at the individual QTL level? Mol Breed 31:265-278

Huang B, Johnson JW, Nesmith DS, Bridges DC (1994) Root and shoot growth of wheat genotypes in response to hypoxia and subsequent resumption of aeration. Crop Sci 34:1538-1544

King IP, Forster BP, Law CC, Cant KA, Orford SE, Gorham J, Reader S, Miller TE (1997) Introgression of salt-tolerance genes from Thinopyrum bessarabicum into wheat. New Phytol 137:75-81

Li HB, Vaillancourt R, Mendham NJ, Zhou MX (2008) Comparative mapping of quantitative trait loci associated with waterlogging tolerance in barley (Hordeum vulgare L.). BMC Genomics 9:401

$\mathrm{Li} \mathrm{HH}$, Ye GY, Wang JK (2007) A modified algorithm for the improvement of composite interval mapping. Genetics 175:361-374

Ma LQ, Zhou EF, Huo NX, Zhou RH, Wang GY, Jia JZ (2007) Genetic analysis of salt tolerance in a recombinant inbred population of wheat (Triticum aestivum L.). Euphytica 153:109-117

Munns R, James RA, Islam AKMR, Colmer TD (2011) Hordeum marinum-wheat amphiploids maintain higher leaf $\mathrm{K}^{+}: \mathrm{Na}^{+}$and suffer less leaf injury than wheat parents in saline conditions. Plant Soil 348:365-377

Parelle J, Dreyer E, Brendel O (2010) Genetic variability and determinism of adaptation of plants to soil waterlogging. In: Mancuso S, Shabala S (eds) Waterlogging signalling and tolerance in plants. Springer-Verlag, Heidelberg, Germany, pp 241-265

Poysa WW (1984) The genetic control of low temperature, iceencasement, and flooding tolerances by chromosomes 5A, 5B, and 5D in wheat. Cereal Res Commun 12:135-141

Qiu FZ, Zheng YL, Zhang ZL, Xu SZ (2007) Mapping of QTL associated with waterlogging tolerance during the seedling stage in maize. Ann Bot 99:1067-1081

Sayre KD, Van Ginkel M, Rajaram S, Ortiz-Monasterio (1994) Tolerance to waterlogging losses in spring bread wheat: effect of time of onset on expression. Annu Wheat Newsl 40:165-171

Samad A, Meisner CA, Saifuzzaman M, Van Ginkel M (2001) Waterlogging tolerance. In: Reynolds MP, Ortiz-Monasterio JI, McNab A (eds) Application of Physiology in wheat breeding. CIMMYT, Mexico, pp 136-144

Settler TL, Waters I (2003) Reviews of prospects for germplasm improvement for waterlogging tolerance in wheat, barley and oats. Plant Soil 253:1-34

Setter TL, Burgess P, Waters I, Kuo J (1999) Genetic Diversity of barley and wheat for waterlogging tolerance in Western Australia. In: Proceedings of the 9th
Australian Barley Technical Symposium. Australian Barley Technical Symposium Inc, Melbourne

Song QJ, Shi JR, Singh S, Fickus EW, Costa JM, Lewis J, Gill BS, Ward R, Cregan PB (2005) Development and mapping of microsatellite (SSR) markers in wheat. Theor Appl Genet 110:550-560

Taeb MR, Koebner MD, Forster BP (1993) Genetic variation for waterlogging tolerance in the Triticeae and the chromosomal location of genes conferring waterlogging tolerance in Thinopyrum elongatum. Genome 36:825-830

Thomson CJ, Colmer TD, Watkin ELJ, Greenway H (1992) Tolerance of wheat. (Triticum aestivum cv. Gamenya and Kite) and triticale (Triticosecale cv. Muir) to waterlogging. New Phytol 120:335-344

Van Deynze AE, Dubcovsky J, Gill KS, Nelson JC, Sorrells ME, Dvofak J, Gill BS, Lagudah ES, McCouch SR, Appels R (1995) Molecular-genetic maps for group 1 chromosomes of triticeae species and their relation to chromosomes in rice and oat. Genome 38:45-59

Van Ooijen JW (2006) JoinMap 4, software for the calculation of genetic linkage maps in experimental populations. In: Kyazma BV (ed) , Wageningen, The Netherlands

Wen YX, Zhu J (2005) Multivariable conditional analysis for complex trait and its components. Acta Genet Sin 32:289-296

Zhang LQ, Liu DC, Yan ZH, Lan XJ, Zheng YL, Zhou YH (2004) Rapid changes of microsatellite flanking sequence in the allopolyploidization of new synthesized hexaploid wheat. Science in China Ser. C. Life Sci 47(6):553-561

Zhou MX, Li HB, Mendham NJ (2007) Combining ability of waterlogging tolerance in barley (Hordeum vulgare L.). Crop Sci 47:278-284

Zhu J (1992) Mixed model approaches for estimating genetic variance and covariance. J Biomath 7:1-11

doi:10.1186/2193-1801-2-245

Cite this article as: Yu and Chen: Conditional QTL mapping for waterlogging tolerance in two RILs populations of wheat. SpringerPlus $20132: 245$

\section{Submit your manuscript to a SpringerOpen ${ }^{\odot}$ journal and benefit from:}

- Convenient online submission

Rigorous peer review

- Immediate publication on acceptance

- Open access: articles freely available online

- High visibility within the field

- Retaining the copyright to your article

Submit your next manuscript at $>$ springeropen.com 